\section{Dr Joseph Connolly}

columns
Formerly Consultant Psychiatrist, the Bethlem Royal and Maudsley Hospital, London

Although this obituary respects Joseph Connolly's modesty in asking for no eulogies at his funeral, it is nevertheless important to record his important contributions to psychiatry, especially his role in developing a new form of community service for the severely mentally ill.

He was born in 1930 in the Tower of London, where his father had been stationed with the Irish Guards, and he went to school in Camberwell. Before attending Westminster Hospital Medical School, he served his National Service with the 1st Battalion Black Watch in 1948, then stationed in Germany. He subsequently joined the Territorial Army in the 21st Special Air Service Regiment (Artists Rifles). After qualifying MBBS (London) in 1956, he was House Officer and Senior House Officer at the Royal London Hospital, and Medical Registrar at the Metropolitan Hospital before moving to Bermuda in 1960. He volunteered for the Royal Naval Reserve, serving as Surgeon Lieutenant and leaving as Surgeon Lieutenant Commander in 1968.

The breadth of Joe's medical career is apparent from his appointments and qualifications. After qualification he obtained the DObstRCOG and DCH in 1958, and MRCP (London) in 1960. He was elected FRCPsych in 1981 and FRCP in 1984. While Joe was a consultant physician in Bermuda at the King Edward VII Memorial Hospital, psychiatric trainees from the Maudsley were being seconded to locum appointments in Bermuda in order to provide a skeleton psychiatric service on the island. Their influence inspired Joe to apply to the Maudsley for a training post in 1969. He was appointed after the Dean interviewed him by telephone from Bermuda, a departure from the usual procedure for which he remained touchingly grateful. Soon after passing the MPhil London (1972) and MRCPsych (1973), Joe became Senior Lecturer in Psychiatry at Westminster Hospital Medical School. There he established an effective liaison psychiatric service for which he was well suited as a former physician. He became active in the Society for Psychosomatic Research and was its President from 1987 to 1989

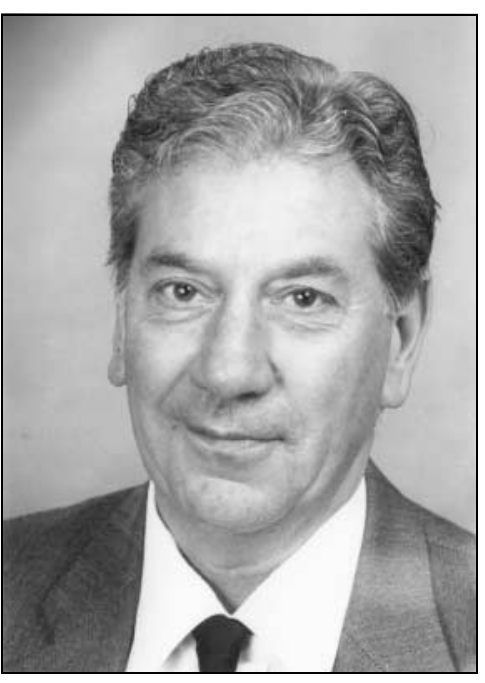

Joe was attracted by research at the Institute of Psychiatry. As Senior Registrar he helped pioneer a 3-year nurse therapytraining programme. He was appointed as Consultant Psychiatrist to the Bethlem Royal and Maudsley Hospital in the early 1980s.

As Consultant Psychiatrist Joe became, among much else, the leader of a clinical research team delivering community care, mainly via nurses, in a 3-year randomised controlled trial. ${ }^{1}$ This compared intensive assertive outreach at home with usual in-patient-based care in almost 200 people who had acute serious mental illness. They were treated and followed up over 20 months. Community home-based care generally included a few days in hospital followed by intensive assertive outreach care at home by the team led by Joe. Its problem-oriented approach emphasised the enhancement of patients' daily living skills. The academic researchers and raters were not involved in day-to-day clinical decisions.

Compared with usual hospital care, home-based assertive outreach led to slightly superior clinical outcomes, shorter stay in hospital, and much more satisfaction by patients and relatives alike, all at a significantly reduced cost to the National Health Service. On the negative side, the home-based care group suffered three suicides underlining the high death rates in such patients. Violent and tragic events often provoke over-reaction by the media. This is what happened 14 months after the commencement of the study, perhaps because of the novelty of the research approach. The events were sensationalised in national newspapers, on television and in a Parliamentary Question. The adverse publicity led to a strong reaction in the Maudsley Hospital which had a major impact on Joe as the responsible consultant psychiatrist. One unfortunate repercussion was the loss of clinical control of the home-care team over any admissions of patients. Another was the denting of the clinical team's morale. But further examination of the facts restored the balance. The hospitalbased group also suffered three suicides. A general audit of suicides among all non-study patients admitted to the Bethlem Royal and Maudsley Hospital had revealed disconcertingly high rates in line with rates elsewhere in similar sufferers.

Eventually, a Maudsley audit exonerated and praised the clinical team, and the ethical committee permitted the study to continue. Its result resembled that of similar research in the USA and Australia, and encouraged the spread of homebased care for seriously mentally ill people in the UK.

Though credit for the ultimately fruitful study is due to its entire clinical and research team, Dr Joe Connolly's tact, acumen, resilience and humour maintained morale within the assertive outreach team and overcame further obstacles to completing this multi-faceted study. Joe co-authored eight scientific papers on aspects of community care.

Joe suffered a major reverse when he developed cancer of the colon with early spread. There followed long periods of chemotherapy which he bore with stoicism knowing that the outcome might be grave. He took early retirement in 1994. Fortunately, he had a full and permanent remission and was bemused when his oncologist discharged him from further follow-up after 10 years.

Joe was always resistant to adversity with a gentle and perceptive sense of humour. His administrative skills, sense of fair play and friendliness made him a natural candidate for key positions within the Bethlem Royal and Maudsley Hospital. He was elected Chairman of its medical committee in 1991 and of its ethics committee around the same time.

He died peacefully after collapsing at home on 25 September 2008 and leaves behind his wife Marguerite (Rita), his five children and eight grandchildren.

\section{Gerald Russell and Isaac Marks}

\section{doi: 10.1192/pb.bp.109.026955}

1 Marks IM, Connolly J, Muijen M, Audini B, McNamee G, Lawrence RE. Home-based versus hospital-based care for people with serious mental illness. BrJ Psychiatry1994; 165: 179-194. 